\title{
DESign AND DEVElopMENT OF CALIBRATION UNIT FOR PRECISION PLANTER
}

\author{
Tejminder Kaur ${ }^{1}$, Dilip Kumar ${ }^{2}$ \\ ${ }^{1,2}$ Academic and Consultancy Services-Division \\ Centre for Development of Advanced Computing(C-DAC), Mohali, India \\ ${ }^{1}$ er.tejminder@gmail.com \\ ${ }^{2}$ dilipecdac.in
}

\begin{abstract}
The critical parameters for plant population with desired planting geometry include uniform distribution and precision placement of seeds. $R \& D$ efforts in metering of single seeds at predetermined intervals are carried in this paper. Proximity sensor technique based seed spacing evaluation system that measure time intervals between seeds and transmission ratio between two velocities is use to determine planter seed spacing uniformity. The calibration unit includes frame light barrier sensor that consists of square crosssection window including transmitter and receiver with innovative microcontroller technology in its casing along with the inductive type gear tooth sensor that calculates rpm of roller. For acquiring the data serially to personal computer the system includes circuitry to interface the sensors with the AT89S52 microcontroller. Mechanical mechanism of motor/roller/ SMU is controlled using V/F drive through PC itself. Calibration of whole system is based on ISO defined standard parameters that are Quality of feed index, multiple index and Miss index. This calibration unit can be used instead of grease belt stand to rapidly obtain quantitative evaluations of planter seed spacing uniformity in the laboratory.
\end{abstract}

\section{KEYWORDS}

Frame light barrier sensor, gear tooth sensor, SMU, 1 hp AC motor, Yaskawa J1000 AC drive, RS232 and USB communication.

\section{INTRODUCTION}

State-of-art designs of pneumatic precision planters are lacking. As of now, no manufacturer in India is engaged in commercial production of precision planters which can be used for direct seeding of vegetables. R\&D efforts are required to develop a pneumatic precision planter which can be used for a variety of vegetable seeds. Seed spacing is important particular for vegetable crops where seed spacing uniformity has been demonstrated to be a significant factor in yield. With uniform spacing crop can grow to maximum size and fill the row space, without being pushed out of the row. The distance between plants within row influenced by a number of factors including variability of seed metering unit and seed dropping, failure of a seed to be dropped and multiple seed drop at the same time. Due to the individual volumes of wheel metering systems each holding more than one seed, seed meters provide random seed distribution. Performance of a planter has remarkable influences on yield in agriculture products and especially its seeding uniformity is a crucial index in estimation of seeders quality.

There are several techniques for determining the planter performance (jasa and dickey, 1982; brooks and church, 1987; kachman and smith, 1995; karayal et al, 2005; S.Ebrahimian, H.R Gassemzadeh, 2011).

DOI : $10.5121 /$ ijcsea.2013.3302 
Janke and Erbach (1985) used manual method of determining space by making direct measurement from removed soil of marked section of row. Singh et al (2005) used grease belt method for manually measuring the seed spacing but it imposed some limitations on timing constraints as it is time consuming and data acquiring constraint as data obtained will be limited by length of belt. Few field based performance were also made. Kepner et al. (1987) measured the distance between the plants after growth and performance indices were calculated .M. F. Kocher, Y. Lan, C. Chen, J. A. Smith (1998) describes an opto-electronic seed spacing evaluation system that measured time intervals between seeds and detected front-to-back location of seed drop events relative to the planter was used to rapidly determine planter seed spacing uniformity in the laboratory. Raheman and Singh (2003) developed a sensor based on light interference technique for sensing the seed droppings from planter. D. Karayel, M. Wiesehoff, A.Ozmerzi, J. Muller (2005) describes a high-speed camera system for evaluating seed spacing uniformity and velocity of fall of seeds. The performance of the high-speed camera system in terms of seed spacing evaluation was compared with a sticky belt test stand, used as a reference. Coefficient of variation of seed spacing, velocity of fall and coefficient of variation of velocity of fall of seeds decreased as the speed of the metering rollers increased. Wei Li, Jiachun Lin (2006), a testing approach for seeding precision was developed which was an integrated technology of machine vision, pattern recognition, and automatic control. A machine vision based test-bed was developed for performance tests of grain seeders and a corresponding software package was compiled to capture the images of the deposited seeds, to segment the seeds from the background of the image, and to calculate the spacing between two seeds after precision seeding, the number of seeds per length after drill seeding, and the distance between hills and the number of seeds per hill after hill-drop seeding.

Most of the test beds were designed for testing a certain type of seeder. For example, the precision planter tester was used for testing drill seeders, a hill drop planter and a seeder. In this paper a new approach had been done for testing planter performance based on seeds by calibrating its performance on based of few parameters which include quality of feed index, miss index and multiple index .

\section{Circuit diagram}

Variable frequency drive, $1 \mathrm{HP}$ motor, roller, smu, frame light barrier sensor, proximity gear tooth sensor and ATMEL microcontroller are the main component of calibration unit.

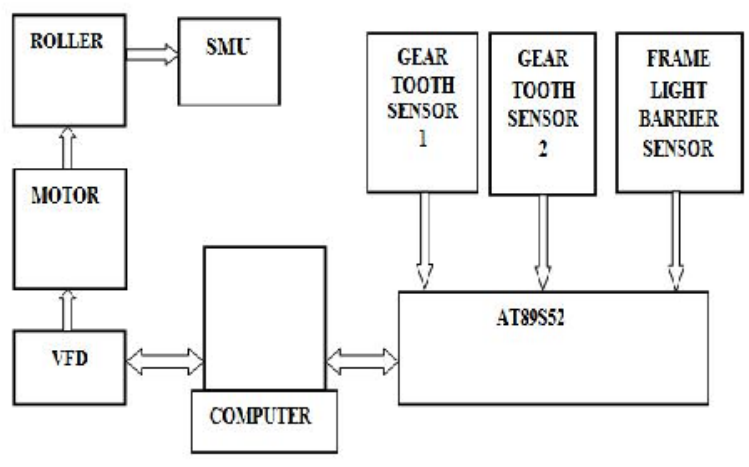

Figure 1. Block diagram of Calibration unit 


\section{MATERIALS AND METHODS}

\subsection{Seeds}

Mustard seeds were being used for this study. The specification for the diameter of this seed was between $1.5 \mathrm{~mm}$ to $4 \mathrm{~mm}$.

\subsection{Calibration unit setup}

A sticky belt stand was used as a reference to monitor seed spacing of seed metering unit (Figure. 2). An ac motor of $1 \mathrm{hp}$ was used to drive the roller on which belt was being mounted. The seed meter mechanism was driven by the belt test stand to provide the theoretical seed spacing via the meter-to-belt transmission ratio. The seed drill unit was positioned over the sticky belt. A pair of gear tooth sensors was being attached to roller and SMU unit respectively for calculating RPM of roller and SMU for calculating transmission ratio. Frame light barrier sensor was used for calculating time interval between falling seeds.

During the test process, roller was driven by a motor, which made the belt move forward. The rotation speed of the motor was adjusted by software via V/F j1000 Yaskawa drive. Roller then provides rotation speed to SMU through the mechanism of gear tooth and sprocket used to drive SMU.

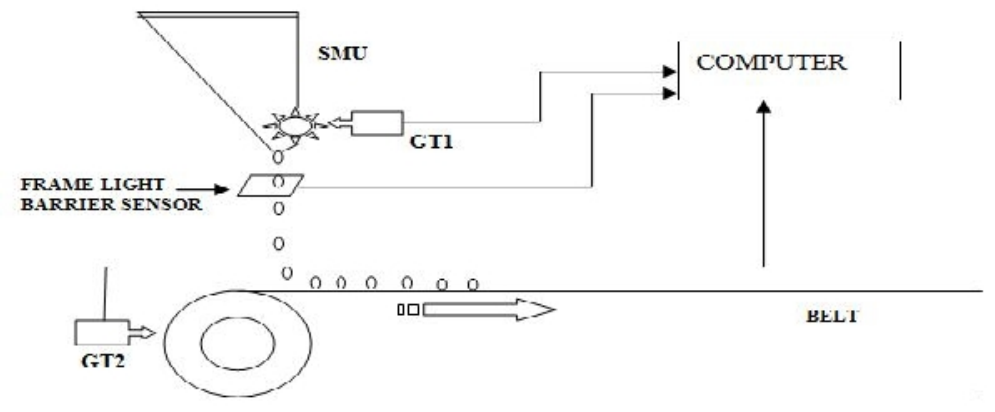

Figure 2. Planter Rig test

\subsection{Embedded hardware}

Di-Soric Frame light barrier (OGWSD 25 P3K-TSSL) and two FUZI inductive type (12 mm diameter) proximity gear tooth sensors combination was used to detect time interval between falling seeds from the SMU, roller and SMU speed respectively and the working mechanism of sensors was controlled by combination of ATMEL 8051C microcontroller and relays using external and timer interrupts. The sensed data of sensors was then transmitted serially to PC for further analysis.

\subsection{Computer software}

Yaskawa engineering tool Drive Wizard Plus helps managing specific drive settings on the PC. The advanced functionality of DriveWizard Plus is window-based application that assists all users with powering up the drive, test running the application, or performing maintenance (Figure 3).V/F Driver settings were done with the help of this software through which we drive the motor by changing relevant frequency parameter which further provide speed to SMU. 
The data acquisition portion of the program that include acquiring data from sensors was written in assembly language in order to be fast enough to detect every passing seed and accurately measure rpm. Flash magic is window based application that helps in acquiring data from microcontroller through USB serial interface (Figure. 4).

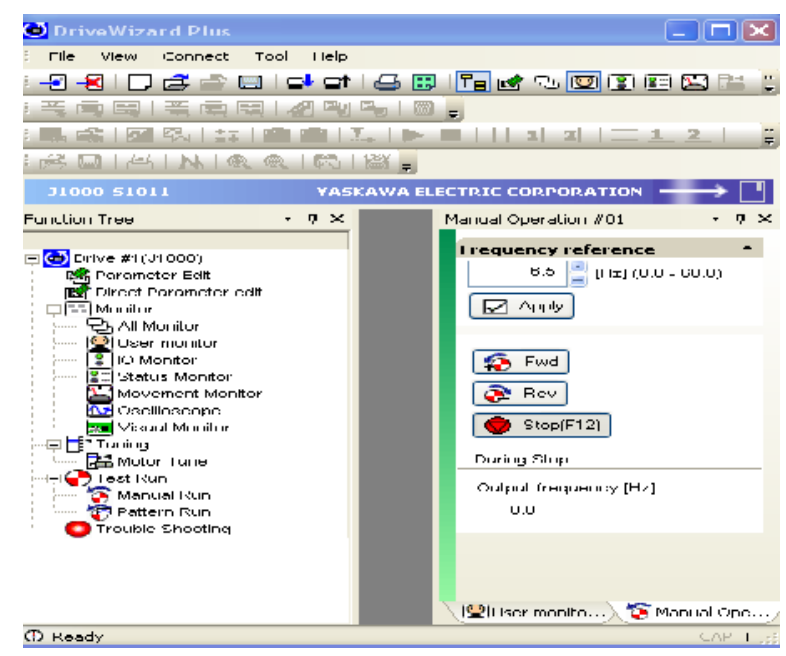

Figure 3. DriveWizard Software

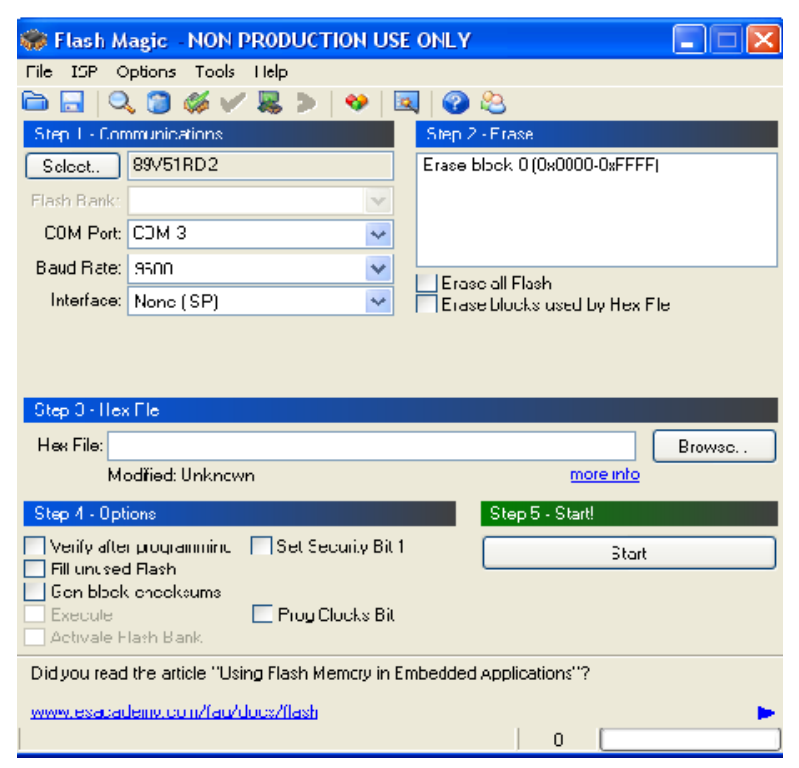

Figure 4. Software for Acquiring Microcontroller Data

\subsection{Calibration procedure}

A number of measures based on the theoretical spacing for the planter were defined by the International Organization for Standardization in ISO Standard 7256/1-1984 (E) (ISO, 1984). These measures included the quality of feed index, multiples index and miss index. The theoretical spacing is the spacing that would occur if there were no misses, multiples, or variability. In this study, target spacing was determined from the planter drive rotational speed and the drive speed ratio, and used as the theoretical spacing. Normally sown seeds as defined in 
the ISO standard are those having seed spacings within the range from one-half times the theoretical spacing to 1.5 times the theoretical spacing.

Yaskawa j1000 VFD was being used to provide variable frequencies to motor for acquiring initial conditions .SMU unit got its speed through motor via roller and gear mechanism. Transmission ratio between roller and SMU was changed using sprockets that were attached to SMU. We selected three pairs of sprockets for it having teeth combinations $(15,15),(15,19),(15,21),(15$, $23)$, (15, 25). VFD was controlled through PC using serial communication using S232/J component.

The SMU having fixed number of holes i.e. 30 and all open was positioned over the roller belt. The roller speed on which the belt mounted was actually duplicating the tractor wheel speed in normal planter conditions. The frame light barrier sensor was positioned under the seed tube and just above the belt. The sensor was attached to the set up stand to minimize relative motion between the SMU and sensor. For calculating actual RPM Two proximity sensor named gear tooth sensors were attached to gear having 40 teeth that was fixed to the shaft connecting to the roller so that it provide same rpm as roller and to the gear also having 40 teeth attached to upper sprockets of SMU respectively .

The SMU, sticky belt and sensors combination with a simulated roller travel with the speed as set by frequency parameter using VFD was run with wheat seeds. The setup was started and run for $20 \mathrm{~s}$ or so to reach steady-state operating conditions before the sensor system was signalled to start recording time interval along with rpm measuremnets.theoretical distance between seeds was being calculated from the planter drive rotational speed and the drive speed ratio

The sensor system was being signalled one by one using electronic hardware to calculate actual spacing. As soon as the frame light barrier system recorded the time interval for 25 seeds, the setup was stopped at the same time. Sensed data was being assessed by microcontroller and was transmitted to PC side by side and was being analysed. Each time the roller/SMU/electronic sensor system was run, it yielded about 25 seed spacings for which different spacing measurements can be compared.

\section{ANALYSIS AND RESULTS}

The system was capable of varying the speed of planting by using a VFD system. As the frequency was being changed using software the speed of motor also varies. The line graph shows the variations in motor speed in terms of RPM with change in VFD frequency (Hz)through PC (Figure 5).

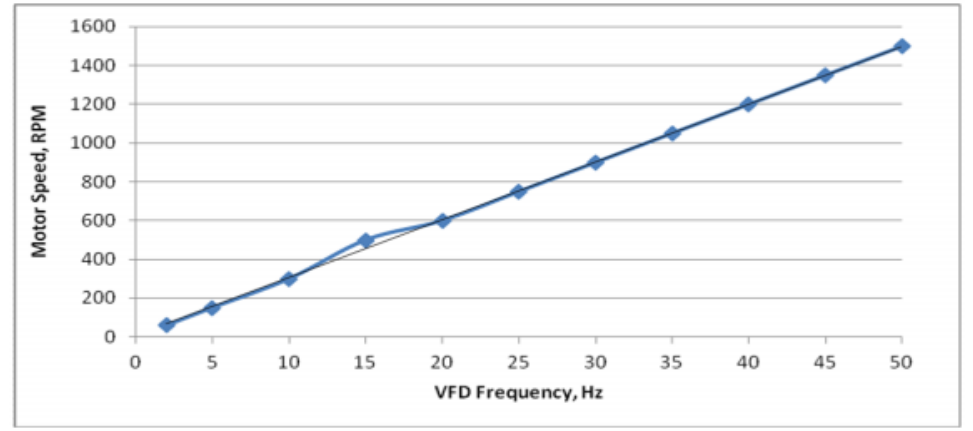

Figure 5. Variation of motor rpm with change in VFD frequency. 
The gear tooth sensor system worked well in obtaining the rpm of roller and SMU unit with only 1 to $2 \%$ deviation from theoretical calculations that is being acceptable in speed dimensions. Frame light barrier sensor provided the actual seed intervals between fallen seeds that were afterwards converted to distance.

While calibrating the unit we come to notice that changing the sprocket ratio of SMU also changes the theoretical spacing and so the actual spacing when measured. Increasing the number of teeth in sprocket attached to SMU increases the theoretical spacing. Figure 6 shows the effect on theoretical spacing when the transmission ratio between the sprockets was changed at constant frequency of $5.4 \mathrm{~Hz}$ (randomly selected for calibrating) to motor which gives $50 \mathrm{rpm}$ to roller.

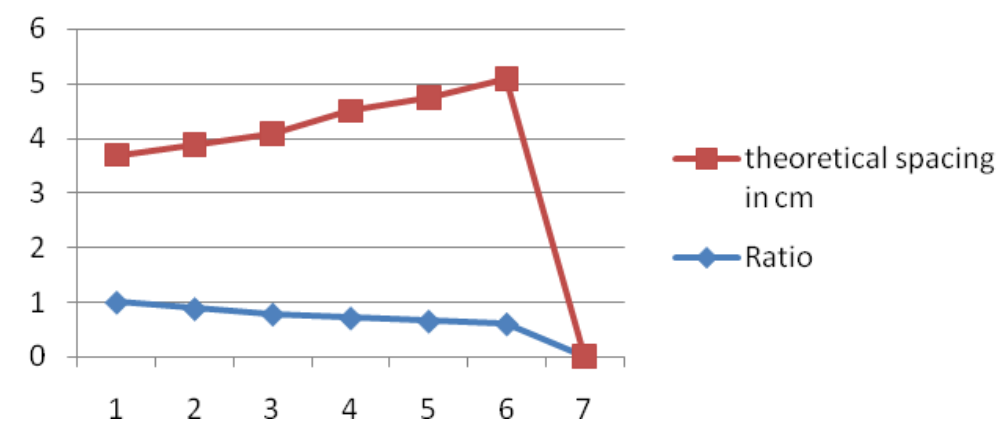

Figure 6. Theoretical spacing variations with sprocket teeth ratio .

Providing fixed vacuum to SMU, calibration unit was tested for mustard seeds at frequency provided by VFD to motor that gives theoretical spacing of $11 \mathrm{~cm}$. The frequency of occurrence to seed spacing graph (Figure 7) shows the distribution of seed spacing to regions that were defined by ISO for quality of feed index, multiples and misses.ISO defined the region $(0.5 \mathrm{x}$ to $1.5 \mathrm{x})$ as quality of feed index where $\mathrm{x}$ is theoretical spacing.

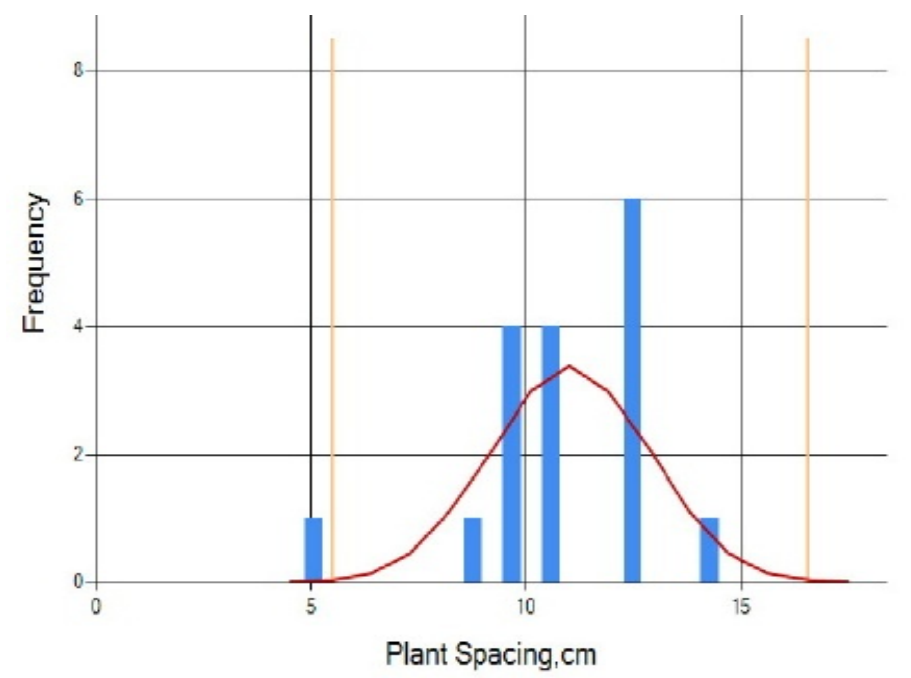

Figure 7. Distribution of seed spacings in regions

By analysing the acquired data we got that $90 \%$ of quality of feed index that shows that the actual spacings were close to theoretical spacings. The peak in red line shows the theoretical spacing that is near about $11 \mathrm{~cm}$, blue bar defines the seed spacing the fall into different regions. The 
region inside 2 yellow lines depicts the region $(0.5 \mathrm{x}$ to $1.5 \mathrm{x})$ for quality of feed index. The region $(0.0 .5 \mathrm{x})$ is for misses and the region above $1.5 \mathrm{x}$ depicts multiples.

\section{CONClusions}

Frame light barrier sensor provides high resolution from $0.7 \mathrm{~mm}$ diameter, short response time of $0.1 \mathrm{~ms}$ and is shock resistive. It improves the electronic measurement of seed spacing. The calibration unit incorporates information of seed drop events relative to the planter with seed interval timing and planter travel speed to obtain the seed spacing data. The ISO standard normal seed spacing measurements achieved with the sensor system using seed time interval, proves the accurate designing and development of calibration unit.

\section{REFERENCES}

[1] M.F.Kocher, Y.Lan, C.Chen, J.A.Smith, "Opto-electronic sensor system for rapid evaluation of planter seed spacing uniformity" Vol. 41(1):pp. 237-245, 1998.

[2] H. Navid, S. Ebrahimian, H.R. Gassemzadeh, M.J. Mousavi nix," Laboratory evaluation of seed metering device using image processing method" Australian journal of agriculture engineering Vol 2(1) pp. 1-4,2011

[3] D.Karayel, M.Wiesehoff, A.Ozmerzi, J.Muller, "Laboratory measurement of seed drill seed spacing and velocity of fall of seeds using high-speed camera system" Computers and Electronics in Agriculture. pp. 89-96, 2006

[4] W.Li, J.Lin, "Seeding Precision Test Based on Machine Vision" 2006.

[5] P.Rohrbach, R.D.Brazee, H.J.Barre, "On Spacing Statistics of Plant Populations Produced by UnIform Seed-placement Devices" pp. 210-225, 1969.

[6] M.R.Maleki, J.F.Jafari, M.H. Raufat, A.M. Mouazen, J. De Baerdemaeker, "Evaluation of Seed Distribution Uniformity of a Multi-flight Auger as a Grain Drill Metering device", Biosystems Engineering Vol. 94(4), pp. 535-543, 2006.

[7] I. Ozturk, Y. Yildirim, S. Hinislioglu, B. Demir and E. Kus, "Optimization of seed flow evenness of Scientific Research and Essays Vol. 7(1), pp. 78-85, 2012

\section{AUTHORS BIOGRAPHY}

Dilip Kumar received his $\mathrm{PhD}$ in Engineering and Technology from Maharishi Markandeshwar University (MMU), Ambala, India in 2010, ME in Electronics Product Design and Technology from PEC University of Technology (formerly Punjab Engineering College), Chandigarh in 2003, and BE in Electronics and Telecommunication Engineering from Army Institute of Technology, University of Pune, India in 2000. He is currently a Senior Engineer at Centre for Development of Advanced Computing, a premier Research and Development Institute of Ministry of Information Technology, Government of India. His research interests include wireless sensor networks, fault tolerance and embedded system. He has published more than 90 papers in international journal/conferences.

Tejminder kaur has received the B.Tech. (Electronics and Communication Engineering) degree from the Lovely School of Sciences, Phagwara affiliated to Lovely Professional University, Phagwara in 2010, and presently she is doing M.Tech (Embedded Systems) degree from Centre for development of Advanced Computing (CDAC), Mohali and working on her thesis work.

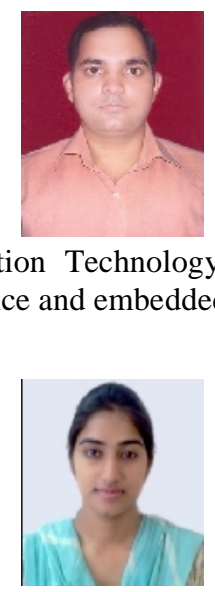

